\title{
Square Wave Voltammetric Determination of 2-Thiouracil in Pharmaceuticals and Real Samples Using Glassy Carbon Electrode
}

\author{
Naveen M. Gokavi, Vijay P. Pattar, Atmanand M. Bagoji, and Sharanappa T. Nandibewoor \\ P. G. Department of Studies in Chemistry, Karnatak University, Dharwad 580003, India \\ Correspondence should be addressed to Sharanappa T. Nandibewoor; stnandibewoor@yahoo.com
}

Received 19 September 2013; Revised 19 November 2013; Accepted 3 December 2013

Academic Editor: María Isabel Pividori

Copyright (C) 2013 Naveen M. Gokavi et al. This is an open access article distributed under the Creative Commons Attribution License, which permits unrestricted use, distribution, and reproduction in any medium, provided the original work is properly cited.

A simple and rapid method was developed using cyclic and square wave voltammetric techniques for the determination of tracelevel sulfur containing compound, 2-thiouracil, at a glassy carbon electrode. 2-thiouracil produced two anodic peaks at $0.334 \mathrm{~V}$ and $1.421 \mathrm{~V}$ and a cathodic peak at $-0.534 \mathrm{~V}$. The square wave voltammetry of 2-thiouracil gave a good linear response in the range of $1-20 \mu \mathrm{M}$ with a detection limit of $0.16 \mu \mathrm{M}$ and quantification limit of $0.53 \mu \mathrm{M}(0.0679 \mu \mathrm{g} / \mathrm{g})$, which is in good agreement as per IUPAC definition of trace component analysis $(100 \mu \mathrm{g} / \mathrm{g})$. The obtained recoveries range from $98.10 \%$ to $102.1 \%$. The proposed method was used successfully for its quantitative determination in pharmaceutical formulations and urine as real samples.

\section{Introduction}

In order to meet the growing demands for the new drugs (less costly, quite effective, and with minimum side effects) to fight against diseases, newer drugs are being pushed into the market at a greater extent that it has become difficult to keep abreast of their merits and demerits; so, a strict control on the quality of the drugs and their therapeutic actions become important. Hence, the pharmaceutical analysis plays a pivotal role in quality assurance. Thiouracil refers both to a specific molecule consisting of a sulfated uracil and a family of molecules based upon the structure. The substance is historically relevant in the preparation of antithyroid drug. Sulfhydryl compounds are known to undergo electrochemical oxidation at solid electrodes, but their oxidation occurs at relatively high potentials $[1,2]$. It was characterized for the electrocatalytic oxidation of sulfhydryl compounds. 2thiouracil (Scheme 1) and its derivatives also act as selective inhibitors of nitric oxide synthase (NOS) [3]. The administration of 2-thiouracil in chicken has been found to cause increase in total protein content and decrease in DNA content [4]. Results of some derivatives of 2-thiouracil, such as propylthiouracil, which was used as antithyroid drug, produced thyroid cancers in human and in some animals such as mice, rats, and hamsters [5]. Several methods have been reported for the determination of 2-thiouracil in complex physiological samples such as liquid chromatography coupled with electrochemical detection [6] and spectral studies [7]. However, these methods suffer from some disadvantages such as high cost, long analysis time, sample pretreatment, low sensitivity and selectivity, which make them unsuitable for routine analysis. In most of the chemical oxidations of 2-thiouracil, S-S linked dimer is obtained as the major product [8-10]. However electrochemical oxidation studies of 2-thiouracil has not attracted much attention. Hence it was considered interesting to study electrochemical oxidation of 2-thiouracil at glassy carbon electrode using square wave voltammetry.

The advance in experimental technique in the field of analysis of drugs is due to their simplicity, low cost, and relatively short analysis time when compared with the other techniques. Electrochemical methods have proved to be very sensitive for the determination of organic molecules, including drugs and related molecules in pharmaceutical dosage forms and biological fluids [11-15]. Carbon electrodes, especially glassy carbon electrodes (GCE), are widely used 


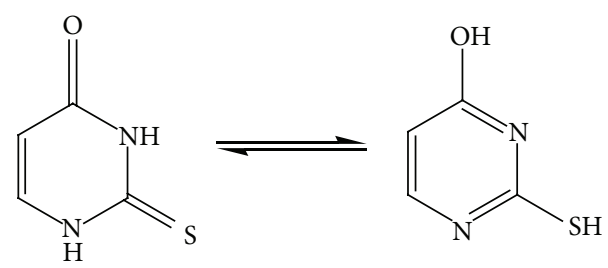

SCHEme 1: Chemical structure of 2-thiouracil.

in the electrochemical investigations because of their low background current, wide potential windows, chemical inertness, low cost, and suitability for detection of various organic and biological compounds. To our knowledge, voltammetric determination of 2-thiouracil using GCE has not been reported so far. The objective of the present work is to develop a convenient and sensitive method for the determination of 2-thiouracil. Hence we report the electrochemical behaviour of 2-thiouracil and its determination at GCE using square wave and cyclic voltammetry techniques. It was further successfully applied for the sensitive and selective determination of 2-thiouracil in pharmaceutical formulations and real samples.

\section{Experimental}

2.1. Materials and Reagents. The powdered form of 2thiouracil was obtained from Sigma Aldrich and used without further purification. A stock solution $\left(1 \times 10^{-3} \mathrm{M}\right)$ of 2 thiouracil was prepared in millipore water. The phosphate buffers from $\mathrm{pH}$ 3-10.4 were prepared in millipore water as described by Christian and Purdy [16]. All other reagents used were of analytical or reagent grade and their solutions were prepared with millipore water.

2.2. Instrumentation. Electrochemical measurements were carried out on a CHI $630 \mathrm{D}$ electrochemical analyzer $(\mathrm{CH}$ Instruments Inc., USA). The voltammetric measurements were carried out in a $10 \mathrm{~mL}$ single compartment threeelectrode glass cell with $\mathrm{Ag} / \mathrm{AgCl}$ as a reference electrode, a platinum wire as counter electrode, and a $3 \mathrm{~mm}$ diameter glassy carbon electrode (GCE) as the working electrode. All the potentials are given against the $\mathrm{Ag} / \mathrm{AgCl}(3 \mathrm{M} \mathrm{KCl})$. All experiments were carried out at an ambient temperature of $25^{\circ} \mathrm{C} \pm 0.1^{\circ} \mathrm{C}$. The $\mathrm{pH}$ measurements were performed with Elico LI120 pH meter (Elico Ltd., India).

At different scan rates, the area of the electrode was calculated using $1.0 \mathrm{mM} \mathrm{K}_{3} \mathrm{Fe}(\mathrm{CN})_{6}$ as a probe. For a reversible process, the Randles-Sevcik formula has been used [17]:

$$
i_{\text {pa }}=\left(2.69 \times 10^{5}\right) n^{3 / 2} A D_{0}^{1 / 2} C_{0} v^{1 / 2},
$$

where $i_{\mathrm{pa}}$ refers to the anodic peak current, $n$ is the number of electrons transferred, $A$ is the surface area of the electrode, $D_{0}$ is diffusion coefficient, $v$ is the scan rate, and $C_{0}$ is the concentration of $\mathrm{K}_{3} \mathrm{Fe}(\mathrm{CN})_{6}$. For $1.0 \mathrm{mM} \mathrm{K}_{3} \mathrm{Fe}(\mathrm{CN})_{6}$ in $0.1 \mathrm{M}$ $\mathrm{KCl}$ electrolyte, $n=1$ and $D_{0}=7.6 \times 10^{-6} \mathrm{~cm}^{2} \mathrm{~s}^{-1}$ [17]; then from the slope of the plot of $i_{\mathrm{pa}}$ versus $v^{1 / 2}$ relation, the surface area of electrode was calculated. In our experiment, the slope obtained was $2.59 \times 10^{-6}$ and the surface area of glassy carbon electrode was calculated to be $0.035 \mathrm{~cm}^{2}$.

2.3. Analytical Procedure. The GCE was carefully polished using $0.3 \mu \mathrm{m} \mathrm{Al}_{2} \mathrm{O}_{3}$ slurry on a polishing cloth before each experiment. After polishing, the electrode was rinsed thoroughly with water. After this mechanical treatment, the GCE was placed in buffer solution and various voltammogramms were recorded until a steady state baseline voltammogram was obtained.

The GCE was first activated in phosphate buffer ( $\mathrm{pH} 3.0)$ by cyclic voltammetric sweeps between -1.2 and $2.0 \mathrm{~V}$ until stable cyclic voltammograms were obtained. Then electrodes were transferred into another $10 \mathrm{~mL}$ of phosphate buffer ( $\mathrm{pH}$ 3.0) containing proper amount of 2-thiouracil. After accumulating for $10 \mathrm{~s}$ at open circuit under stirring and following quiet for $10 \mathrm{~s}$, potential scan was initiated and cyclic voltammograms were recorded between -1.2 and $2.0 \mathrm{~V}$, with a scan rate of $50 \mathrm{mVs}^{-1}$. All measurements were carried out at room temperature of $25 \pm 0.1^{\circ} \mathrm{C}$.

\section{Results and Discussion}

3.1. Cyclic Voltammetric Behavior of 2-Thiouracil. In order to understand the electrochemical behaviour at the glassy carbon electrode, cyclic voltammetry was carried out with 2-thiouracil between pH 3.0 and 10.4 of phosphate buffer, which produced two well-defined oxidation peaks and one reduction peak. The cyclic voltammograms of 2-thiouracil at $\mathrm{pH} 4.2$ in phosphate buffer were as shown in Figure 1. The blank solution without 2-thiouracil was shown by curve (b) and anodic peaks corresponding to 2-thiouracil oxidation appeared at $0.334 \mathrm{~V}$ (peak A) and $1.421 \mathrm{~V}$ (peak B) and a cathodic peak at $-0.534 \mathrm{~V}$ (peak $\mathrm{C}$ ) as shown in curve (a).

It is shown that the reduction peak was observed in the reverse scan, suggesting that the electrochemical reaction was a quasireversible process [19]. Nevertheless, it was found that the oxidation peak current of 2-thiouracil showed a remarkable decrease during the successive cyclic voltammetric sweeps. After every sweep, the peak current decreased greatly and finally remained unchanged. This phenomenon may be attributed to the consumption of adsorbed 2-thiouracil on the electrode surface or due to the fact that the adsorption of oxidative product occurs at the electrode surface. Therefore, the voltammograms corresponding to the first cycle and peak $\mathrm{B}$ were generally recorded, since peak B was more intense than $\mathrm{A}$.

3.2. Influence of $p H$. The electrochemical oxidation of 2thiouracil was studied with different supporting electrolytes such as Britton-Robinson buffer and phosphate buffer. Within the range of $\mathrm{pH} 3.0-10.4$, the phosphate buffer gave the good results as compared to other supporting electrolytes. 


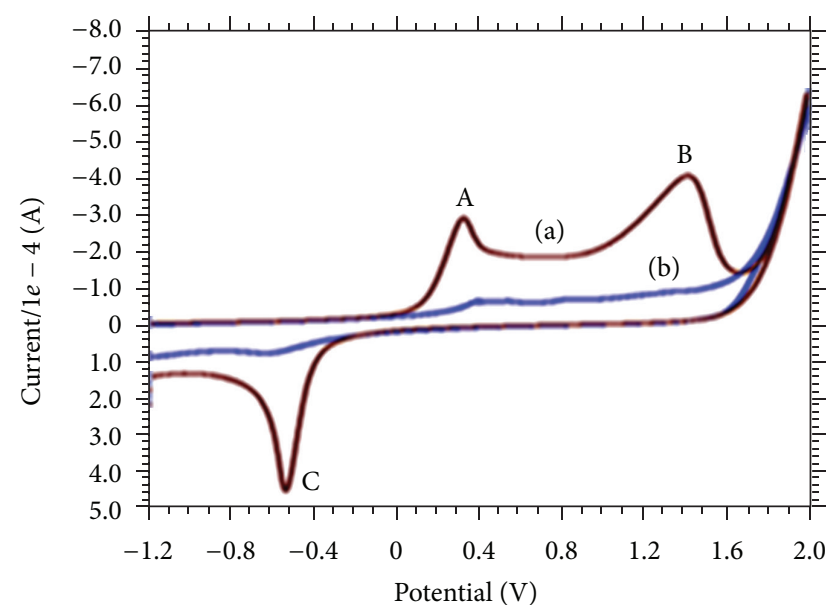

FIGURE 1: Cyclic voltammogram obtained for $1 \mathrm{mM}$ 2-thiouracil on glassy carbon electrode in $\mathrm{pH}$ 4.2, 0.2 M buffer: (a) 2-thiouracil and (b) blank run without 2-thiouracil at $v=50 \mathrm{mVs}^{-1}$ (A and B are oxidation peaks whereas $\mathrm{C}$ is reduction peak).

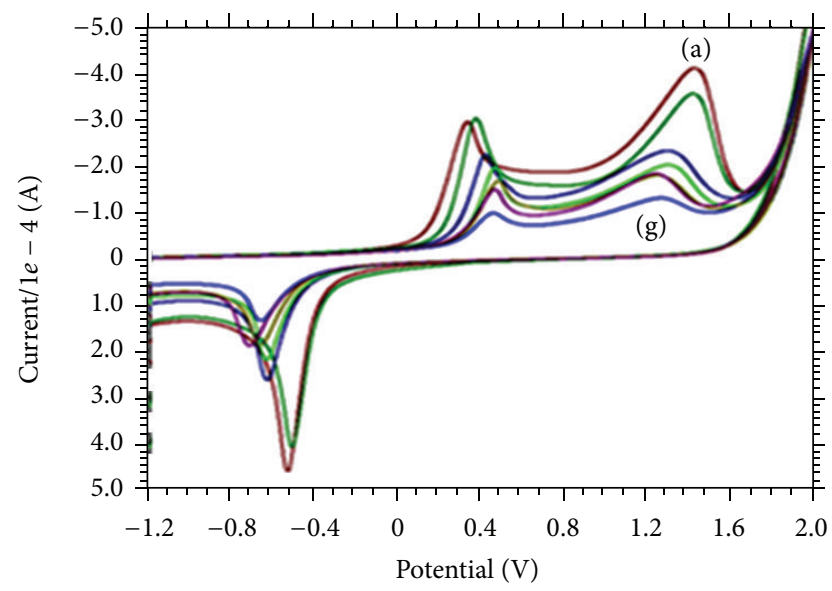

FIgURE 2: Influence of $\mathrm{pH}$ on the shape of the peaks in phosphate buffer solution at (a) $\mathrm{pH} 4.2$, (b) $\mathrm{pH} 3.0$, (c) $\mathrm{pH} 5.0$, (d) $\mathrm{pH} 7.0$, (e) $\mathrm{pH} 8.0$, (f) $\mathrm{pH} 9.2$, and (g) $\mathrm{pH} 10.4$ with potential scan rate $50 \mathrm{mV} \mathrm{s}^{-1}$.

Hence phosphate buffers were taken as a supporting electrolyte. With increasing the $\mathrm{pH}$ of the buffer solution, the peak potential shifted to less positive values as shown in Figure 2.

The plot of $E_{p}$ versus $\mathrm{pH}$ (Figure 3(a)) shows that the peak potential is $\mathrm{pH}$ dependent. The variation of peak current with $\mathrm{pH}$ is shown in Figure 3(b). Initially the peak current increased from $\mathrm{pH} 3$ to 4.2 and then decreased from $\mathrm{pH} 4.2$ to 10.4 . The voltammetric response was markedly dependent on $\mathrm{pH}$. From the experimental results (Figure 2) it is observed that highest peak current and better shape of the voltammogram was observed at $\mathrm{pH} 4.2$, suggesting that $\mathrm{pH}$ is optimal $\mathrm{pH}$ value. From the plot of current versus $\mathrm{pH}$ (Figure 3(b)) it is evident that at $\mathrm{pH}$ values higher than 10 , the half peak potential is rather constant, indicating that in solutions with $\mathrm{pH}$ greater than 10 , the process is not $\mathrm{pH}$ dependent. It can be concluded that 2-thiouracil in buffered solutions with $\mathrm{pH}$ greater than 10 exist mainly as thiolate anions and therefore their equilibrium concentrations do not

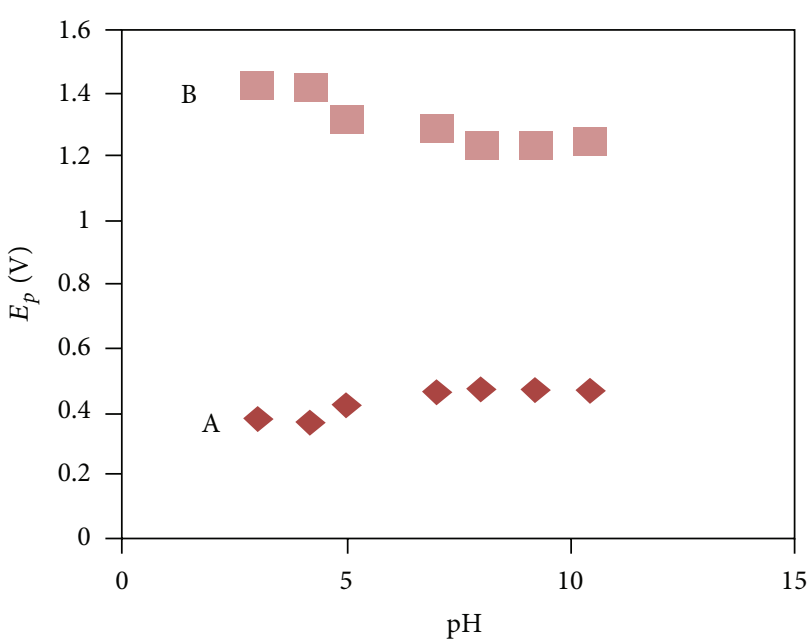

(a)

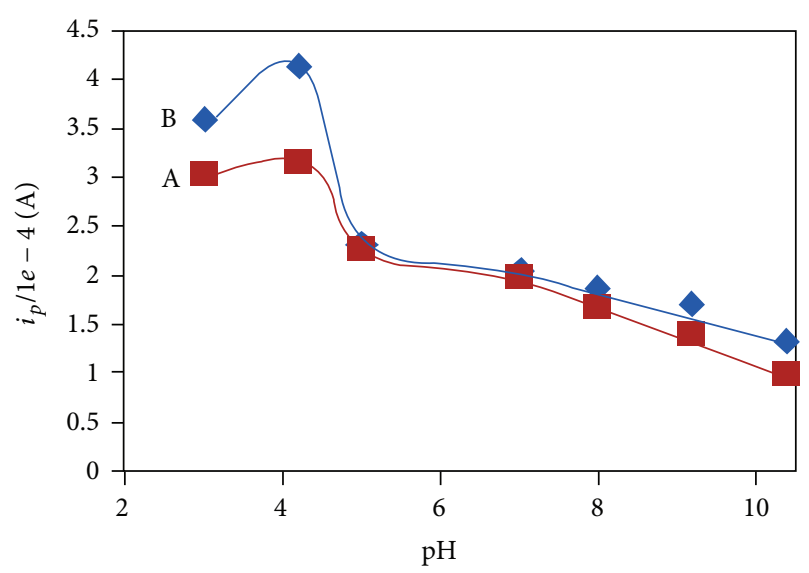

(b)

FIGURE 3: (a) Influence of $\mathrm{pH}$ on the peak potential of 2-thiouracil for peaks A and B. (b) Variation of peak currents of peaks A and B with $\mathrm{pH}$.

vary by increasing the $\mathrm{pH}$ of solution. Hence $\mathrm{pH}$ variation is restricted to 10.4 .

3.3. Influence of Scan Rate. Useful information involving electrochemical mechanism usually can be acquired from the relationship between peak current and scan rate. Therefore, the electrochemical behavior of 2-thiouracil at different scan rates from 50 to $250 \mathrm{mVs}^{-1}$ (Figure 4) was also studied. From this we observed that by increasing the scan rate, the peak potential of B was shifted to more positive values. Simultaneously, the width at half-height of peak B increased. It is suggested that this corresponds to the oxidation of 2thiouracil dimers formed at the GCE surface. The formation of such kind of dimers is well documented in the literature [7] (Scheme 2), but they can only be observed when high scan rates are used probably because they have short life time. At the same time, the cathodic peak $\mathrm{C}$ is displaced to more negative values whereas its current increases with the scan rate. 


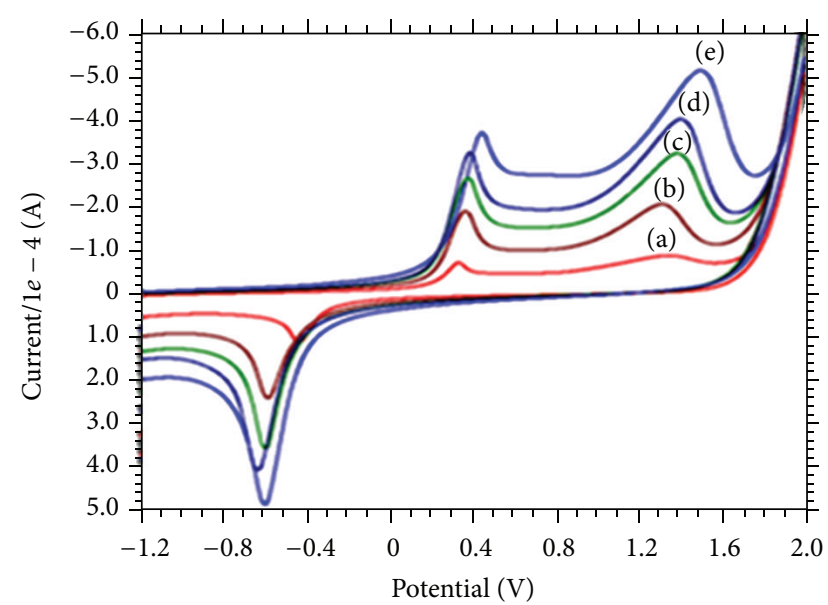

Figure 4: Cyclic voltammograms of $1.0 \mathrm{mM}$ 2-thiouracil on GCE with different scan rates at (a) 50, (b) 100, (c) 150, (d) 200, and (e) $250 \mathrm{mVs}^{-1}$.

There is a good linear relationship between peak current and scan rate. The equations are

$$
\begin{aligned}
& i_{p}\left(10^{-4} \mathrm{~A}\right)=16.06 v\left(\mathrm{Vs}^{-1}\right)+0.253, \quad r=0.998 \\
& i_{p}\left(10^{-4} \mathrm{~A}\right)=20.14 v\left(\mathrm{Vs}^{-1}\right)+0.064, \quad r=0.997
\end{aligned}
$$

for peaks A and B, respectively, as shown in Figure 5(a). In addition, there was a linear relation between $\log i_{p}$ and $\log v$, corresponding to the following equation:

$$
\begin{aligned}
& \log i_{p}\left(10^{-4} \mathrm{~A}\right)=0.988 \log v\left(\mathrm{Vs}^{-1}\right)+1.304, \quad r=0.998 \\
& \log i_{p}\left(10^{-4} \mathrm{~A}\right)=0.892 \log v\left(\mathrm{Vs}^{-1}\right)+1.165, \quad r=0.999
\end{aligned}
$$

for peaks A and B, respectively (Figure 5(b)). The slope of 0.988 and 0.892 is close to the theoretically expected value of 1 for an adsorption controlled process [20].

The peak potential shifted to more positive values with increasing the scan rates. The linear relationship between peak potential and logarithm of scan rate can be expressed as

$$
\begin{aligned}
& E_{p}(\mathrm{~V})=0.126 \log v+0.487, \quad r=0.901, \\
& E_{p}(\mathrm{~V})=0.261 \log v+1.598, \quad r=0.986
\end{aligned}
$$

for the peaks A and B, respectively (Figure 5(c)).

Figure 4 depicts a family of $\mathrm{CV}$ recorded in the system at different potential scan rates. From this figure it was possible to gather information shown in Table 1 regarding the influence of the potential scan rate on the voltammetric parameters of the system. From the variation of $\Delta E$ values with the potential scan rate, shown in Table 1, one may conclude, in this case, that the 2-thiouracil electrochemical oxidation at GCE is a quasireversible mass transfer-controlled process; see Figures 5(a) and 5(d). However the behavior of the ratio $\left|i_{\mathrm{pc}} / i_{\mathrm{pa}}\right|$ for both the peaks (A and $\mathrm{B}$ ) may indicate the presence of a coupled chemical reaction [21]. On the basis of similar voltammetric behaviour observed in the present study, the same mechanism may be proposed as given in [7] (Scheme 2).

3.4. Calibration Curve. In order to develop a rapid and sensitive voltammetric method for determining the 2-thiouracil, we adopted the square wave voltammetric (SWV) mode, because the peaks were sharper and better defined at lower concentration of 2-thiouracil than those obtained by cyclic voltammetry, with low background current, resulting in improved resolution. According to the obtained results, it was possible to apply this technique to the quantitative analysis of 2 -thiouracil. The phosphate buffer solution of $\mathrm{pH} 4.2$ was selected as the supporting electrolyte for the quantification of 2-thiouracil as it gave maximum peak current at $\mathrm{pH}$ 4.2. The peak at about $1.05 \mathrm{~V}$ in SWV was considered for the analysis. Square wave voltammograms obtained with increasing amount of 2-thiouracil showed that the peak current increased linearly with increasing concentration, as shown in Figures 6(a) and 6(b).

Using the optimum conditions described above, linear calibration curves were obtained for 2-thiouracil in the range of 1 to $20.0 \mu \mathrm{M}$. The linear equation was

$$
i_{p}(\mu \mathrm{A})=0.166 C(\mu \mathrm{M})+7.925 \quad(r=0.995) .
$$

Deviation from linearity was observed for more concentrated solutions, due to the adsorption of oxidation product on the electrode surface. It was also observed that the peak potential $\left(E_{p}\right)$ and half peak potential $\left(E_{p} / 2\right)$ were shifted towards more positive value suggesting that product undergoes adsorption at the surface of GCE. Related statistical data of the calibration curve was obtained from five different calibration curves. The limit of detection (LOD) and quantification (LOQ) were $0.16 \mu \mathrm{M}$ and $0.53 \mu \mathrm{M}$, respectively. The LOD and LOQ were calculated using the following equations:

$$
\mathrm{LOD}=\frac{3 s}{m}, \quad \text { LOQ }=\frac{10 s}{m},
$$

where $s$ is the standard deviation of the peak currents of the blank (five runs) and $m$ is the slope of the calibration curve. Comparison of earlier methods with the present method showed the present method was better for the determination of 2-thiouracil (Table 2).

3.5. Stability and Reproducibility. In order to study the stability and reproducibility of the electrode, a $10 \mu \mathrm{M} 2$-thiouracil solution was measured with the same electrode (renewed every time) for every several hours within day; the RSD of the peak current was $0.69 \%$ (number of measurements $=5$ ). As to the between-day reproducibility, it was similar to that of within a day if the temperature was kept almost unchanged which could be attributed to the excellent stability and reproducibility of GCE.

3.6. Effect of Interferents. For the analytical applications of the proposed method, the effects of potential interferents that 


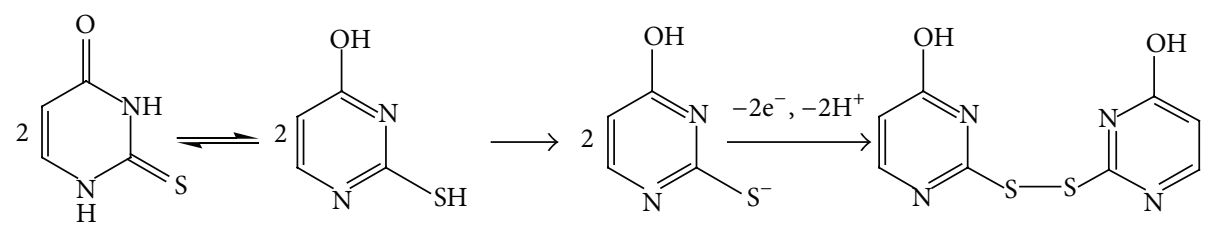

Scheme 2: Proposed mechanism.

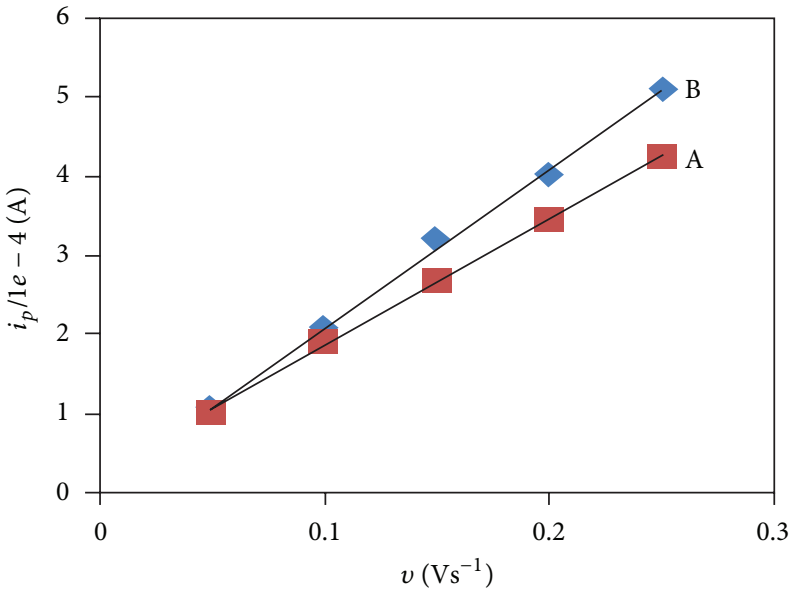

(a)

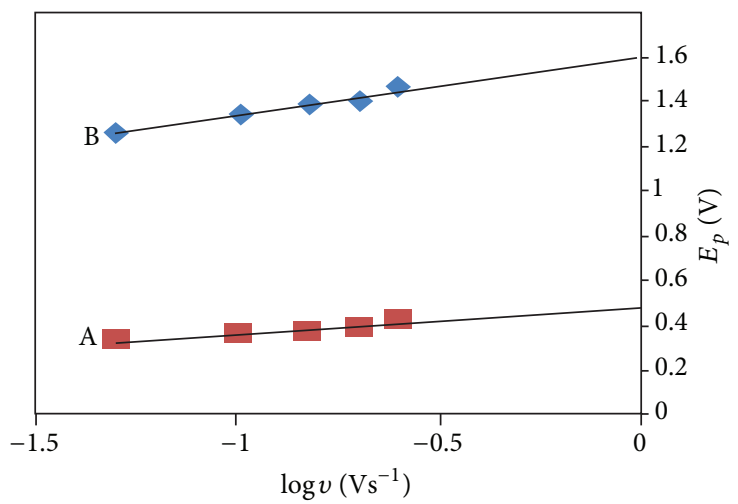

(c)

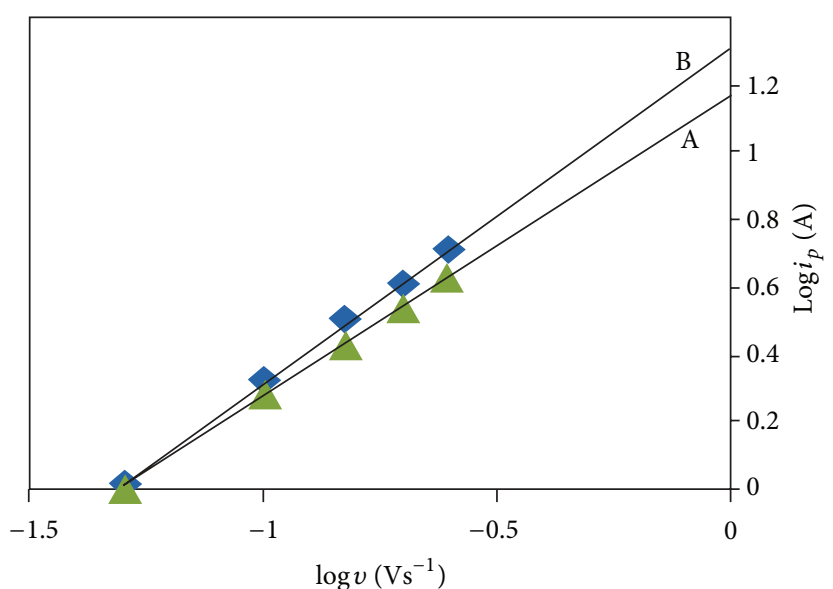

(b)

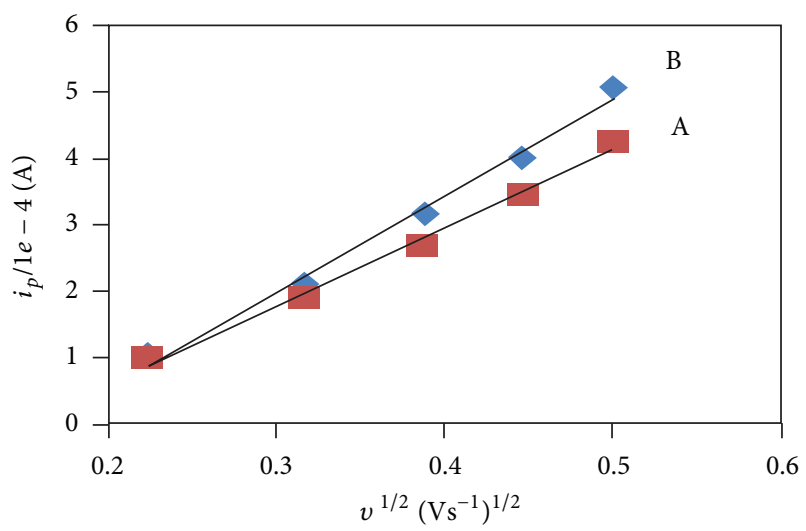

(d)

Figure 5: (a) Dependence of the oxidation peak current of peaks A and B on the scan rate. (b) Dependence of the logarithm of peak current on logarithm of scan rate for peaks A and B. (c) Relationship between peak potential and logarithm of scan rate for the peaks A and B. (d) Relationship between peak current of peaks $\mathrm{A}$ and $\mathrm{B}$ on the square root of scan rate.

TABLE 1: Variation of the voltammetric parameters as a function of the potential scan rate $(v)$ corresponding to the CVs shown in Figure 4.

\begin{tabular}{|c|c|c|c|c|c|c|c|c|c|c|}
\hline $\begin{array}{l}v \\
\left(\mathrm{mVs}^{-1}\right)\end{array}$ & $\begin{array}{l}E_{\mathrm{pa}_{\mathrm{A}}} \\
(\mathrm{mV})\end{array}$ & $\begin{array}{l}E_{\mathrm{pa}_{\mathrm{B}}} \\
(\mathrm{mV})\end{array}$ & $\begin{array}{l}E_{\mathrm{pc}} \\
(\mathrm{mV})\end{array}$ & $\begin{array}{c}\Delta E_{\mathrm{A}} \\
\left(E_{\mathrm{pa}_{\mathrm{A}}}-E_{\mathrm{pc}}\right) \\
(\mathrm{mV})\end{array}$ & $\begin{array}{c}\Delta E_{\mathrm{B}} \\
\left(E_{\mathrm{pa}_{\mathrm{B}}}-E_{\mathrm{pc}}\right) \\
(\mathrm{mV})\end{array}$ & $\begin{array}{c}i_{\mathrm{pa}_{\mathrm{A}}} \\
/ 10^{-4}(\mathrm{~A})\end{array}$ & $\begin{array}{c}i_{\mathrm{pa}_{\mathrm{B}}} \\
/ 10^{-4}(\mathrm{~A})\end{array}$ & $\begin{array}{c}i_{\mathrm{pc}} \\
/ 10^{-4}(\mathrm{~A})\end{array}$ & $\left|\frac{i_{\mathrm{pc}}}{i_{\mathrm{pa}_{\mathrm{A}}}}\right|$ & $\left|\frac{i_{\mathrm{pc}}}{i_{\mathrm{pa}_{\mathrm{B}}}}\right|$ \\
\hline 50 & 32.6 & 125.6 & -50.1 & 82.7 & 175.7 & -1.001 & -1.035 & 1.241 & 1.239 & 1.199 \\
\hline 100 & 36.2 & 134.3 & -59.5 & 95.7 & 193.8 & -1.920 & -2.076 & 2.383 & 1.241 & 1.147 \\
\hline 150 & 37.6 & 137.9 & -61.4 & 98.9 & 199.3 & -2.691 & -3.201 & 3.125 & 1.161 & 0.9762 \\
\hline 200 & 38.5 & 140.3 & -64.6 & 103 & 204.9 & -3.456 & -4.012 & 3.813 & 1.103 & 0.9503 \\
\hline 250 & 42.8 & 145.1 & -70.2 & 113 & 215.2 & -4.251 & -5.102 & 4.262 & 1.002 & 0.8353 \\
\hline
\end{tabular}




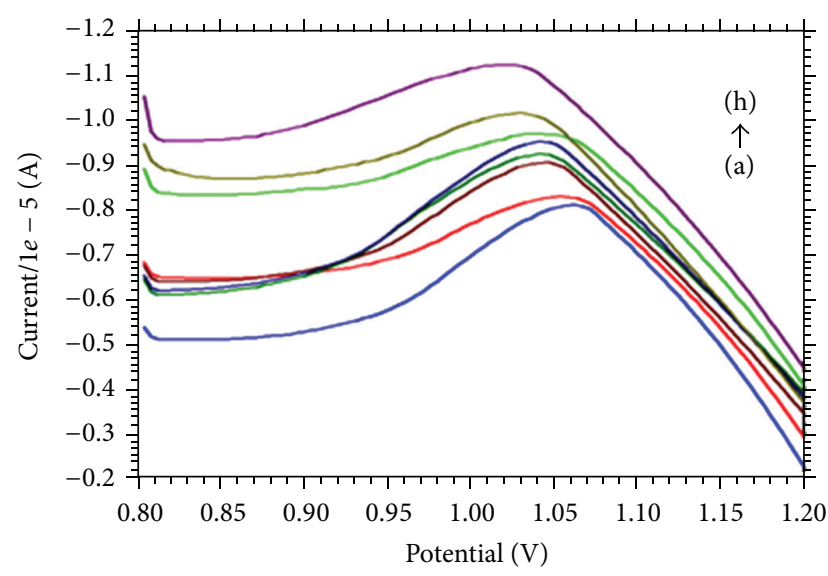

(a)

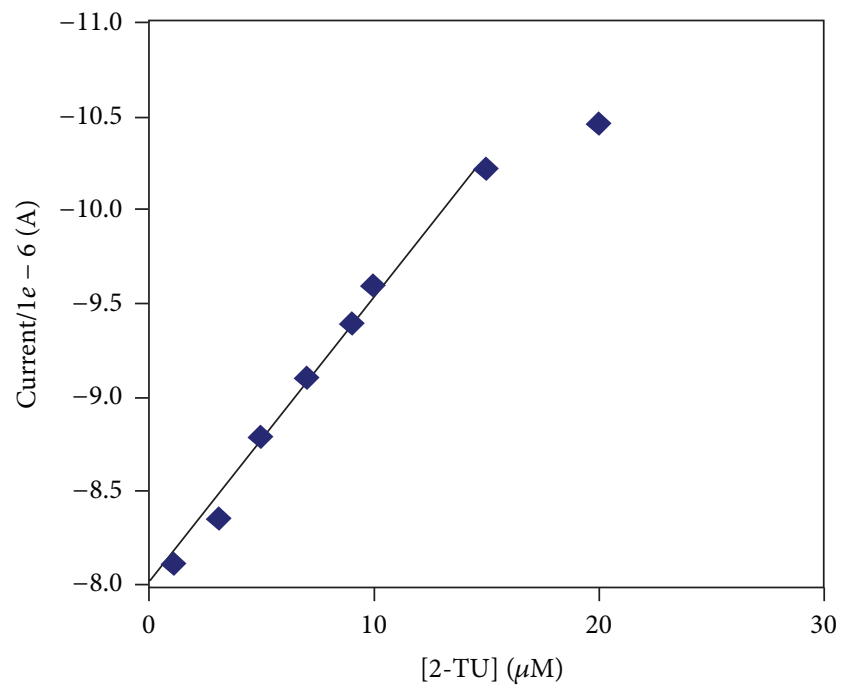

(b)

Figure 6: (a) Square wave voltammograms of GCE in 2-thiouracil solution at different concentrations at (a) 1, (b) 3, (c) 5, (d) 7, (e) 9, (f) 10 , (g) 15 , and (h) $20 \mu \mathrm{M}$ and (b) plot of the peak current against concentration of 2-thiouracil.

TABLE 2: Comparison of some methods for the determination of 2thiouracil with the proposed method.

\begin{tabular}{lccc}
\hline Analytical method & $\begin{array}{c}\text { Linearity range } \\
(\mathrm{mM})\end{array}$ & $\begin{array}{c}\text { Detection limit } \\
(\mu \mathrm{M})\end{array}$ & Ref. \\
\hline $\begin{array}{l}\text { Liquid } \\
\text { Chromatography }\end{array}$ & $(0.5-4.0)$ & $(0.43)$ & {$[6]$} \\
$\begin{array}{l}\text { Carbon-paste } \\
\text { electrode modified } \\
\text { with CoPc }\end{array}$ & $(0.7-800)$ & $(40)$ & {$[18]$} \\
$\begin{array}{l}\text { Glassy carbon } \\
\text { electrode }\end{array}$ & $(0.001-0.015)$ & $(0.16)$ & This work \\
\hline
\end{tabular}

are likely to be in biological samples were evaluated under the optimum experimental conditions. Square wave voltammetric experiments were carried out for $1.0 \mu \mathrm{M}$ 2-thiouracil in the presence of $1.0 \mathrm{mM}$ of each of the interferents. The experimental results (Table 3 ) showed that thousand-fold
TABLE 3: Influence of potential interferents on the voltammetric response of $1.0 \mu \mathrm{M}$ 2-thiouracil.

\begin{tabular}{lcc}
\hline Interferents & Concentration $(\mathrm{mM})$ & Signal change $(\%)$ \\
\hline Citric acid & 1.0395 & 0.18 \\
Dextrose & 1.0320 & 0.93 \\
D-glucose & 1.0850 & -4.4 \\
Gum acacia & 0.9916 & 5.0 \\
Oxalic acid & 1.0157 & 2.6 \\
Starch & 1.0162 & 2.5 \\
Sucrose & 1.0719 & -3.1 \\
\hline
\end{tabular}

TABLE 4: Results of the assay and the recovery test of $2 \mathrm{TU}$ in pharmaceutical preparations using square wave voltammetry.

\begin{tabular}{lc}
\hline & Propylthiouracil tablet \\
\hline Labeled claim $(\mathrm{mg})$ & 50.0 \\
Amount found $(\mathrm{mg})^{\mathrm{a}}$ & 49.0 \\
RSD (\%) & 0.65 \\
Bias (\%) & -2.0 \\
Added (mg) & 5.00 \\
Found (mg) ${ }^{\mathrm{a}}$ & 4.92 \\
Recovered (\%) & 98.4 \\
RSD (\%) & 0.38 \\
Calculated $F$ & 1.24 \\
Calculated $t$ & 2.16 \\
Bias (\%) & -1.6 \\
\hline
\end{tabular}

${ }^{\mathrm{a}}$ Mean average of five determinations.

excess of glucose, starch, sucrose, dextrose, gum acacia, citric acid, and oxalic acid did not interfere with the voltammetric signal of 2-thiouracil. Therefore, the proposed method can be used as a selective method.

3.7. Tablet Analysis and Recovery Test. In order to evaluate the applicability of the proposed method, the commercial medicinal sample containing 2-thiouracil from Propylthiouracil, India, was studied. The tablets were grounded to powder, dissolved in water, and then further diluted so that 2-thiouracil concentration falls in the range of calibration plot. Square wave voltammograms were then recorded under exactly identical conditions that were employed while recording square wave voltammograms for plotting calibration plot. It was found that 2-thiouracil concentration determined for various tablets using this method are in good agreement with the reported values. The values of experimentally determined 2-thiouracil and its amounts agreed reasonably well (Table 4). The typical square wave voltammograms for the 6propylthiouracil solution at GCE are shown in Figure 7(a).

3.8. Detection of 2-Thiouracil in Urine Samples. The applicability of the SWV to the determination of 2-thiouracil in spiked urine was also investigated. The recoveries from urine were measured by spiking drug-free urine with known amounts of 2-thiouracil. The urine samples were diluted 


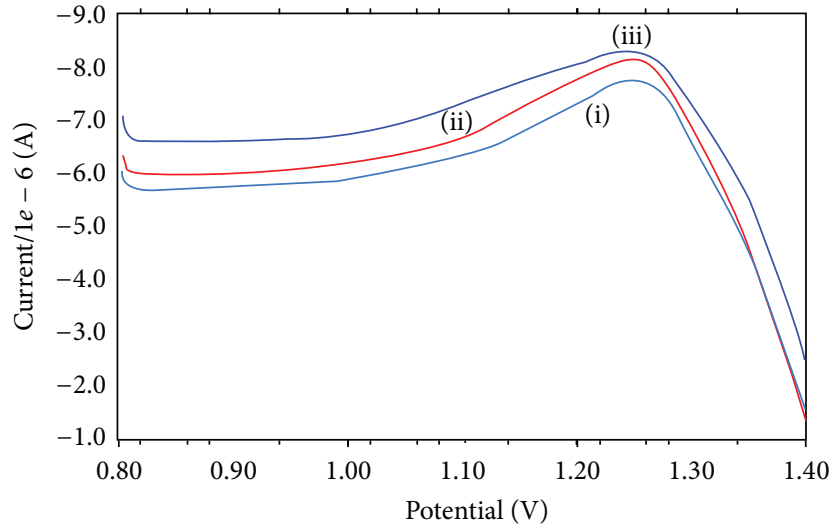

(a)

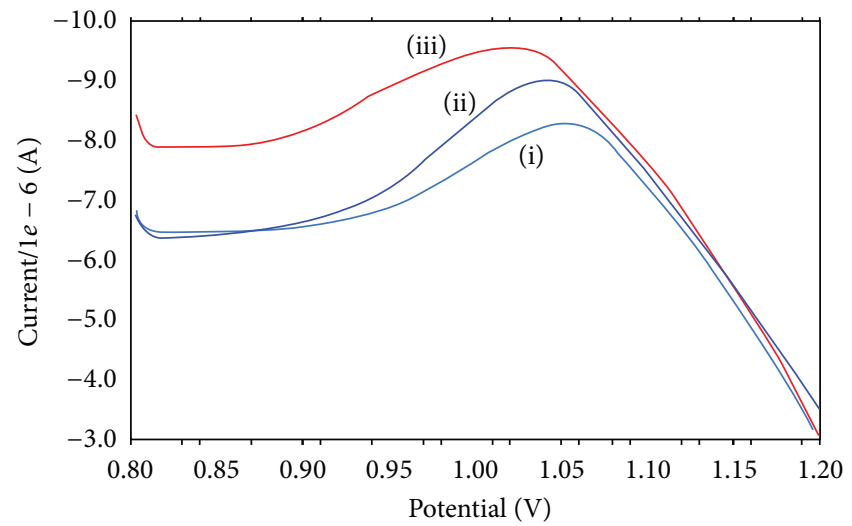

(b)

FIGURE 7: Typical square wave voltammograms on GCE in (a) 6-propylthiouracil solution at different concentrations (i) $2 \mu \mathrm{M}$, (ii) $4 \mu \mathrm{M}$, and (iii) $6 \mu \mathrm{M}$ in tablet solutions and (b) 2-thiouracil solution at different concentrations (i) $2 \mu \mathrm{M}$, (ii) $4 \mu \mathrm{M}$, and (iii) $6 \mu \mathrm{M}$ in urine samples.

TABLE 5: Determination of 2-thiouracil in urine samples.

\begin{tabular}{lccccc}
\hline Urine & Spiked $(\mu \mathrm{M})$ & Detected $^{\mathrm{a}}(\mu \mathrm{M})$ & Bias $(\%)$ & Recovery $(\%)$ & 103.1 \\
Sample 1 & 2 & 2.062 & 3.1 & 101.0 & $0.0301 \pm 0.39$ \\
Sample 2 & 4 & 4.040 & 1.0 & 98.48 & $0.0222 \pm 0.55$ \\
Sample 3 & 6 & 5.909 & -1.5 & 97.66 & $0.0099 \pm 0.17$ \\
Sample 4 & 8 & 7.813 & -2.3 & $0.0207 \pm 0.27$ \\
\hline
\end{tabular}

${ }^{\mathrm{a}}$ Mean average of five determinations.

100 times with the phosphate buffer solution before analysis without further pretreatment. A quantitative determination can be carried out by adding the standard solution of 2thiouracil into the detection system of urine sample. The calibration graph was used for the determination of spiked 2-thiouracil in urine samples. The detection results of four urine samples obtained are listed in Table 5. The recovery determined was in the range from $97.6 \%$ to $103.1 \%$ and the R.S.D. was $0.34 \%$. Thus, satisfactory recoveries of the analyte from the real samples and a good agreement between the concentration ranges studied and the real ranges encountered in the urine samples when treated with the drug make the developed method applicable in clinical analysis. The typical square wave voltammograms for the 2-thiouracil solution at GCE are shown in Figure 7(b).

\section{Conclusion}

The main aim of drug analysis is to contribute to the improvement of drug safety. Due to the poor selectivity of the titrimetric and spectrophotometric assay methods and the insufficient precision of the selective HPLC method, none of these methods can be considered to fulfill this requirement. Nowadays due to advancement in the field of electrochemistry, some other types of electrodes are used to get high sensitivity and selectivity of drugs. A glassy carbon electrode was used for the first time for the oxidation of 2-thiouracil in phosphate buffer solution. A suitable mechanism was proposed. This proposed method can be used for voltammetric determination of selected analyte as low as $0.16 \mu \mathrm{M}$ with good reproducibility. The method offered the advantages of accuracy and time saving as well as simplicity of reagents and apparatus. In addition, the results obtained are successfully applied in pharmaceutical formulations and spiked urine samples. The proposed method is suitable for quality control laboratories as well as pharmacokinetic studies with satisfactory result.

\section{References}

[1] J. P. Hart, Electroanalysis of Biologically Important Compounds, Ellis Horwood, Chichester, UK, 1990.

[2] J. P. Hart and I. C. Hartley, "Voltammetric and amperometric studies of thiocholine at a screen-printed carbon electrode chemically modified with cobalt phthalocyanine: studies towards a pesticide sensor," The Analyst, vol. 119, no. 2, pp. 259263, 1994.

[3] A. Palumbo, M. D'Ischia, and F. A. Cioff, "2-Thiouracil is a selective inhibitor of neuronal nitric oxide synthase antagonising tetrahydrobiopterin-dependent enzyme activation and dimerisation," FEBS Letters, vol. 485, no. 2-3, pp. 109-112, 2000.

[4] I. Roman and R. Giurgea, "Thyroxin and thiouracyl influence upon some biochemical parameters in chicken thymuses," Romanian Journal of Physiology, vol. 36, no. 1-2, pp. 97-101, 1999.

[5] B. M. Dobyns, G. E. Sheline, and J. B. Workman, "Malignant and benign neoplasms of the thyroid in patients treated for hyperthyroidism: a report of the cooperative thyrotoxicosis therapy. Follow up study," Journal of Clinical Endocrinology and Metabolism, vol. 38, no. 6, pp. 976-998, 1974. 
[6] C. Anton and C. Cristian, "Determination of 2-thiouracyl in complex samples By liquid chromatography with electrochemical detection," Romanian Biotechnological Letters, vol. 7, pp. 847854, 2002.

[7] R. N. Goyal, U. P. Singh, and A. A. Abdullah, "Electrochemical oxidation of 2-thiouracil at pyrolytic graphite electrode," Bioelectrochemistry, vol. 67, no. 1, pp. 7-13, 2005.

[8] M. Hepel and R. A. Osteryoung, "Electrochemical behavior of 2-thiouracil on silver electrodes," Journal of Electroanalytical Chemistry, vol. 160, no. 1-2, pp. 217-231, 1984.

[9] P. Swamy and N. Vaz, "Ruthenium(III)- and osmium(VIII)catalyzed oxidation of 2-thiouracil by bromamine-B in acid and alkaline media: a kinetic and mechanistic study," Transition Metal Chemistry, vol. 28, no. 4, pp. 409-417, 2003.

[10] S. Shahrokhian and A. Hamzehloei, "Electrochemical oxidation of catechol in the presence of 2-thiouracil: application to electro-organic synthesis," Electrochemistry Communications, vol. 5, no. 8, pp. 706-710, 2003.

[11] B. Uslu and S. A. Özkan, "Electrochemical characterisation of nefazodone hydrochloride and voltammetric determination of the drug in pharmaceuticals and human serum," Analytica Chimica Acta, vol. 462, no. 1, pp. 49-57, 2002.

[12] J.-M. Kauffmann, M. P. Prete, J.-C. Vire, and G. J. Patriarche, "Voltammetry of pharmaceuticals using different types of modified electrodes," Fresenius Zeitschrift fur Analytische Chemie, vol. 321, no. 2, pp. 172-176, 1985.

[13] F. Belal, H. Abdine, and N. Zoman, "Voltammetric determination of nilvadipine in dosage forms and spiked human urine," Journal of Pharmaceutical and Biomedical Analysis, vol. 26, no. 4, pp. 585-592, 2001.

[14] P. Zuman, "Current status of polarography and voltammetry in analytical chemistry," Analytical Letters, vol. 33, no. 2, pp. 163$174,2000$.

[15] T. B. Demircigil, S. A. Ozkan, O. Coruh, and S. Yilmaz, "Electrochemical behavior of formoterol fumarate and its determination in capsules for inhalation and human serum using differentialpulse and square-wave voltammetry," Electroanalysis, vol. 14, pp. 122-127, 2002.

[16] G. D. Christian and W. C. Purdy, "The residual current in orthophosphate medium," Journal of Electroanalytical Chemistry, vol. 3, no. 6, pp. 363-367, 1962.

[17] B. Rezaei and S. Damiri, "Voltammetric behavior of multiwalled carbon nanotubes modified electrode-hexacyanoferrate(II) electrocatalyst system as a sensor for determination of captopril," Sensors and Actuators B, vol. 134, no. 1, pp. 324-331, 2008.

[18] S. Shahrokhian, A. Hamzehloei, A. Thaghani, and S. R. Mousavi, "Electrocatalytic oxidation of 2-thiouracil and 2-thiobarbituric acid at a carbon-paste electrode modified with cobalt phthalocyanine," Electroanalysis, vol. 16, no. 11, pp. 915-921, 2004.

[19] B. Eswarappa, B. S. Sherigara, and B. E. Kumaraswamy, "Electrochemical investigation of benzelidene benzyl hydrazide and its derivative schiff bases at glassy carbon electrode," Bulletin of Electrochemistry, vol. 20, no. 1, pp. 1-6, 2004.

[20] D. K. Gosser, Cyclic Voltammetry: Simulation and Analysis of Reaction Mechansims, Vancouver Coastal Health, New York, NY, USA, 1993.

[21] S. Corona-Avendaño, G. Alarcón-Angeles, M. T. Ramírez-Silva, G. Rosquete-Pina, M. Romero-Romo, and M. Palomar-Pardavé,
"On the electrochemistry of dopamine in aqueous solution. Part I: the role of [SDS] on the voltammetric behavior of dopamine on a carbon paste electrode," Journal of Electroanalytical Chemistry, vol. 609, no. 1, pp. 17-26, 2007. 

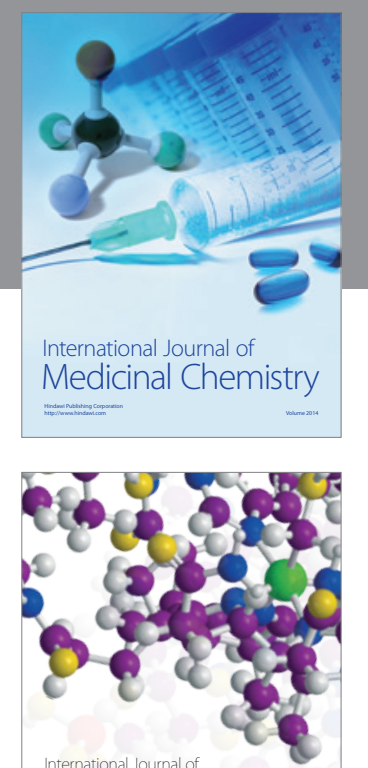

\section{Carbohydrate} Chemistry

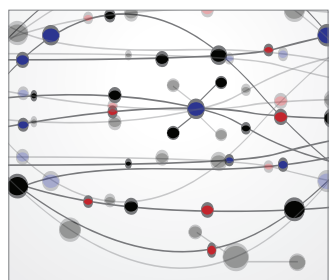

The Scientific World Journal
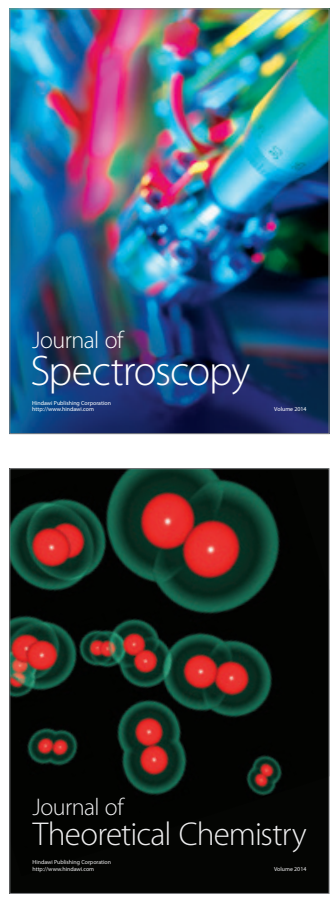
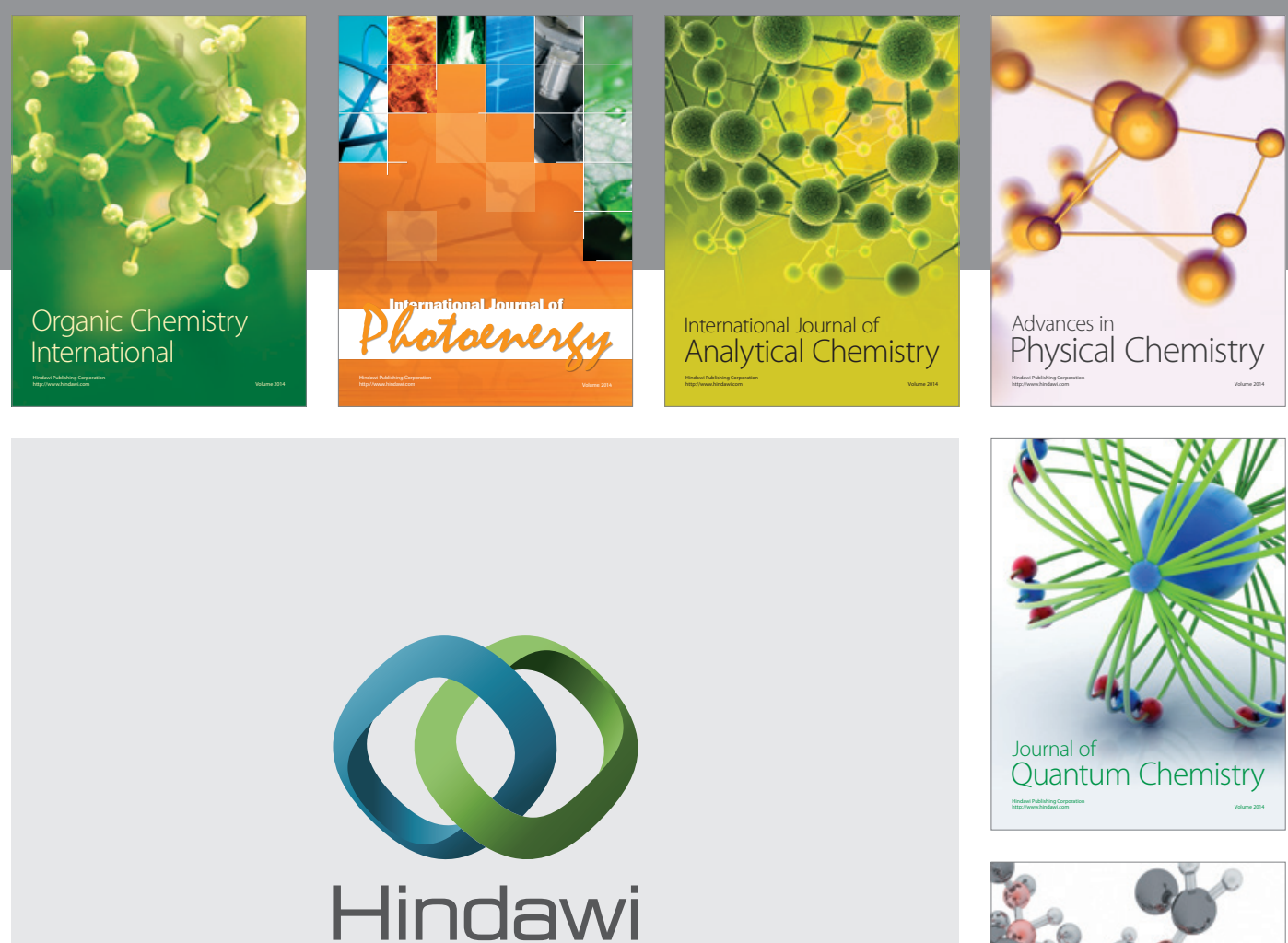

Submit your manuscripts at

http://www.hindawi.com

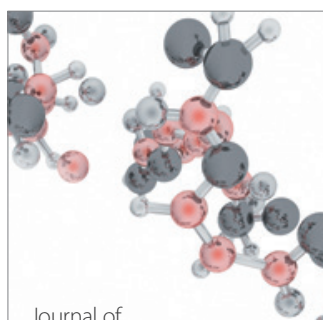

Analytical Methods

in Chemistry

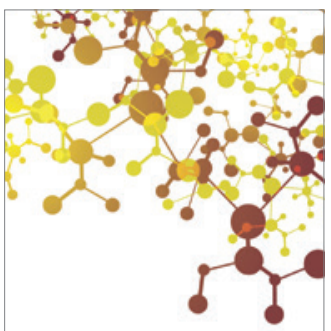

Journal of

Applied Chemistry

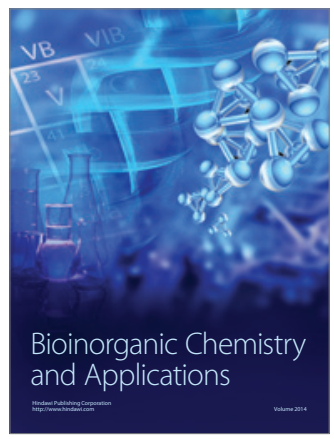

Inorganic Chemistry
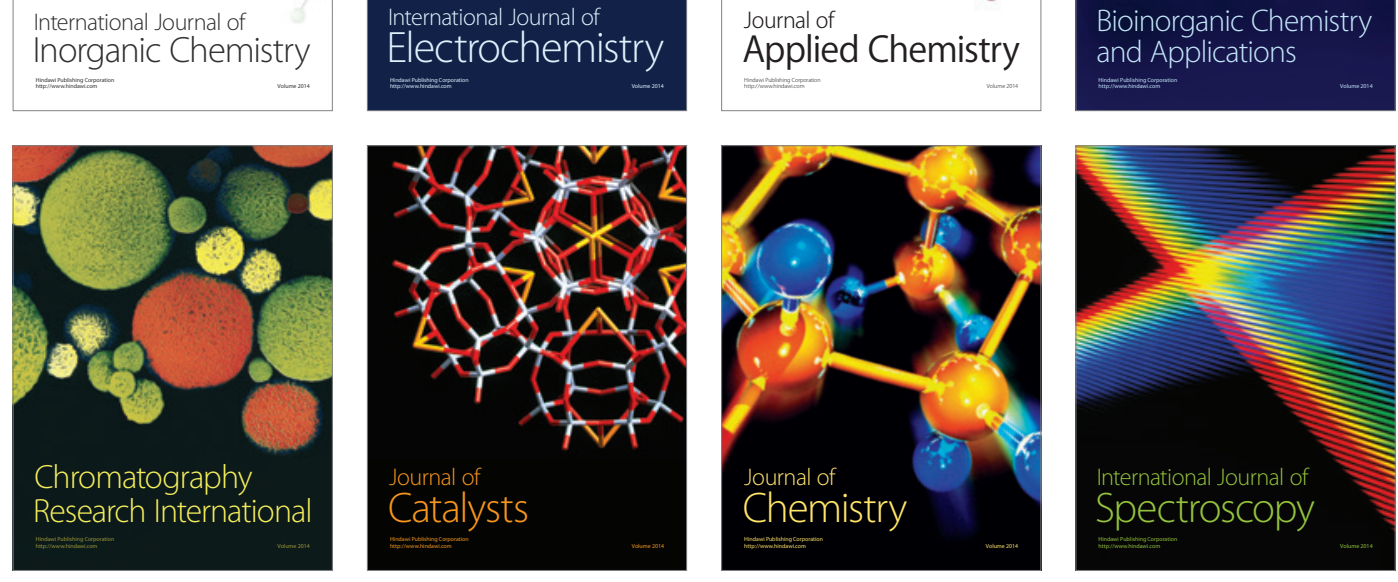